\title{
The Entangling of Problems, Solutions and Markets: On building a market for privacy
}

Daniel Neyland and Sveta Milyaeva

This paper has been published in the journal Science as Culture, online first $19^{\text {th }}$ April 2016: http://www.tandfonline.com/doi/full/10.1080/09505431.2016.1151489

\begin{abstract}
An increasing number of public problems have been subject to market-based interventions as solutions. However, the relationship between problems and solutions in market-based interventions is complex. On occasions solutions are reformulated as understanding of the nature of the problem are advanced. Alternatively, problems are reconfigured to fit a standard solution. Or solutions are said to generate numerous new problems. The complex entangling of problems, solutions and markets can be explored by focusing on the field of online privacy. The complexities of this field can be analysed through three STS treatments of problems and solutions. First, issueproblematisation can be used to understand the ways in which a problem is assembled and comes to form the focus for discussion as an issue can be explored. Second, a paradigm-exemplar approach can assess the extent to which a particular coupling of problem and solution becomes an exemplar for others to draw on. Third, ontological constitution provides a focal point for analysing the ways in which the very nature of entities involved in problems, solutions and markets can be considered. There is analytic utility in each of these approaches in engaging with online privacy regulation and the emerging role of start-ups in introducing new privacy products to an emerging market place. However, these STS approaches leave us with questions regarding the relationship between market solutions and publics, the co-ordination of entities in market solutions and the normative questions that arise from entangling markets, problems and solutions.
\end{abstract}

\section{Keywords}

Online data, Privacy, Problems, Solutions, Science and Technology Studies, Data

Brokers

\section{Introduction}

Various types of market-based interventions have been utilised in policy areas that were once described as the public sector, as a means to resolve (and even simplify and delegate responsibility for) otherwise complex problems. New relations between state and private sector actors or new public private hybrids, forms of competition, rankings and metrics, league tables, contractual bidding and tendering processes, forms of outsourcing, new monitoring processes and pools of money to stimulate innovation, are just some examples of the organisations, devices and actors that have been drawn together to produce market-based interventions to solve a problem.

However, the relationship between problems, solutions and market-based interventions is not always straightforward. On occasions it seems that trade-based 
solutions have to be modified to accommodate the latest definition of a problem, for example, changing understanding of climate change temperature increases, changes the viability of solutions such as carbon trading. At other moments, problems are reworked to fit pre-existing market solutions, for example, when the UK government launched 30 Social Impact Bonds to cover problems as diverse as homelessness, recidivism and care for the elderly, each problem had to be transformed into a cost and a financial risk ${ }^{1}$. There are also market solutions that appear to inspire a number of further problems, for example, a proposed Advanced Market Commitment for malaria vaccines raised numerous concerns of accountability ${ }^{2}$. The aim of this paper will be to ask: how can market-based interventions be analysed through STS studies of problems and solutions?

The history of STS treatments of problems and solutions appears theoretically and empirically diverse. Briefly stated, studies which draw on the heritage of ActorNetwork Theory (ANT), for example, look to forms of problematisation as a basis for making sense of the ways in which an issue comes to be recognised as such (see, for example, Barthe, 2009). Alternatively Kuhn's (1962) work on exemplar solutions to scientific problems is further analysed through Barnes' treatment of such exemplars as sophisticated paradigms (Barnes, 1982, 1985). Work drawing on the social construction of social problems as a basis for analysis has considered the ontological constitution of problems and their solutions (Woolgar and Pawluch, 1985) and draws inspiration from Garfinkel's (1967) analysis of the recursive relationship between problems and solutions.

The paper will begin to explore these STS approaches to problems and solutions through an investigation of emerging attempts to solve the problem of online privacy through markets. Online privacy provides an interesting and timely case as the terms for a market-based solution are currently being developed, opening up opportunities for asking direct questions to participants regarding issues as they are put forward and resolved or at least discussed.

The paper will be structured as follows. We will start by further exploring existing studies of problems and solutions particularly in STS and how this literature intersects with recent studies of markets. We will then explore the online data market and concerns regarding privacy. Initially our discussion will focus on the ways in which markets for online privacy are supported and regulated into being and the consequence of such emerging activities, in particular for privacy and its continual and fluid recasting as problem and solution. Subsequently, our analysis will explore the efforts of start-up organisations to foster a market for privacy through online data control products. The analysis will draw on interviews with start-up organisations and regulators in the field. The paper will conclude with three questions regarding the analytic utility of existing STS approaches to problems and solutions when markets are involved.

\section{Analytical Perspectives}

We will explore three ways in which STS researchers have engaged with problemsolution relationships: (1) issue problematisation; (2) paradigm-exemplar approach; and (3) ontological constitution. ${ }^{3}$ 


\section{Issue-problematisation}

First, we can look to the history of ideas developed through Actor-Network Theory to consider the role of problematisation (Callon, 1986). Here the focus is on investigating the ways a problem comes to be recognised as such and emerges through a network of relations, or more recently an assemblage (a heterogeneous socio-technical arrangement involving objects, humans, procedures, calculative methods, etc) or agencement (an assemblage through which agential effects are sorted out; Caliskan and Callon 2010). Problematisation at times refers to the ways in which actors seek to: 'become indispensable to other actors in the drama by defining the nature and the problems of the latter' (Callon, 1986: 196). This involves proposing particular obligatory courses of action through which such problems ought to be resolved. In this way, the coupling of problem and solution is quite tightly delimited. ${ }^{4}$

On other occasions, problematisation is presented as central to dialogic democracy. Here we might think of assemblages through which issues are brought to the fore, constituted as having a particular nature or made part of a process of discussion in which the nature of the problem is open to participants' contestation (Barthe, 2009; Callon, Lascoumes and Barthe, 2009). The focus in both treatments of problematisation is on how particular issues either come to have a spokesperson or come to have a public or come to be a question for democratic instruments and experiments. As a result, problematisations describe or transform reality, in the process delimiting what must be taken into account and through what means. Following this, we could also consider the publics of problematisations - just who is included and excluded, who is heard and has a voice in discussing particular problems.

In the following analysis we will refer to this approach as issue-problematisation. A strength of this approach for our purposes is that much recent assemblage-based work has turned attention to markets. Hence we find, in the writing of for example Callon (1998), that a market assemblage does not simply emerge but is continuously made and re-made through the work of (in his research) economists, models, calculative devices and more recently experimentation (Muniesa and Callon 2007; Callon 2009) ${ }^{5}$. Market assemblages are said to affirm various demarcations between, for example, relative degrees of value and between the internal and external aspects of the market assemblage. Developing the latter point, Callon argues that forms of assembly work, are neither neutral nor unproblematic: 'framing constitutes powerful mechanisms of exclusion, for to frame means to select, to sever links,' (2007: 140). In this sense, market assembly work can generate clear demarcations between the included and excluded. On the terms of market framings, entities can be rendered valued or valueless.

Furthermore, this recent STS work on markets has begun to engage with some notable problems such as greenhouse gas emissions (MacKenzie, 2009) and nuclear waste (Barthe, 2009) and has begun to touch on the notion of market problematisation. In this way problematisation could become one means for considering processes of market qualification (Sjogren and Helgesson, 2007); that is, how particular things become qualified for entry into market-like activity. To push this formulation of problems and their entanglements with markets further, would involve exploration of who or what might count as a spokesperson in a market situation, or what could come 
to count as a market public - perhaps a public of sufficient value to be considered for inclusion in discussing a problem - and through what activities an issue might become problematised and qualified for entry into market discussions and negotiations.

Marres (2011) offers an extension of these ideas in shifting the focus for attention from problematisation to the constitution of issues and, in so doing, proposes an alternative to the dialogic focus of problematisation. Here Marres suggests that for an issue to become such, does not require a participatory democratic fora, but can instead be traced through the sociomaterial entanglements in which people and things become engaged. For example, smart metres generate a problem-solution type entanglement, encouraging the adoption of a specific definition of what counts as an environmental problem at the same time as adopting a particular solution; namely increased vigilance and economizing of one's energy consumption. The entanglement creates its own form of political participation, centred on its own particular ideals, for example, that participation should be easy and that participation through a metre can encourage - through making visible - notions of efficiency.

In Marres' (2012, 2011; and with Lezaun, 2011) work, engagement then is not presented as a means to increase the knowledge of participants through dialogue or to qualify entities for participation, but as a means to increase the production of preferred - in the case of smart metres, environmentally friendly - solutions. Through metres, to become entangled is to become measured, but it also means to become a feature of the problem-solution relationship. Taking part in smart metering equates to signing up for the solution built into the entanglement (that the metre can help cut energy inefficiency) at the same time as paying recognition to the problem (of environmental effects) and its various translations (through which the problemsolution relationship can also become a means to, for example, save money by having lower fuel bills).

In place of the more participatory, dialogical focus of problematisation comes a focus on sociomaterial entanglements through which actions are produced. The analytic utility of dialogic problematisation and sociomaterial entanglements and the constitution of issues, will be further explored in our empirical analysis. An important question appears to pertain to the ways in which either dialogic or sociomaterial approaches to issue-problematisation could make sense of the specific nature of participants and their role in market-based interventions in public problems. Are they delegates seeking a solution, devices carrying out silent work, entities represented by others, actions (including techniques of calculation, measurement, economizing) rather than people or things?

\section{Paradigm-exemplar}

A second option for exploring problems and solutions is provided by Kuhn and subsequent analyses of his work. We call this the paradigm-exemplar approach in this paper. Kuhn (1962) draws a distinction between a puzzle type problem and other types of problem - a distinction that rests on the degree to which there is the assured existence of a solution. However, particular formulations of problem-solution relationships can become paradigms. Paradigms according to Kuhn can become accepted as the basis on which a problem can and ought to be resolved. A paradigm 
thus generates the assumption that a solution exists and intimates a preferred order to the problem-solution relationship. Barnes $(1982,1984,1985)$ uses Kuhn's treatment of paradigm problem-solutions or exemplars, to explore consensual rather than individual, epistemological achievement. In this way, the Kuhnian paradigmexemplar is: 'used much as a precedent is used in a court of law: scientists actively interpret its significance and agree between themselves what its implications are.' (Barnes, 1984: n.p.).

Rather than providing a singular set of instructions for how to proceed, the paradigmexemplar is hence a problem-solution to be actively engaged, used and built upon. Following this path, a market solution such as environmental cap and trade policies, might become a paradigmatic exemplar; an approved set of actors, processes and relationships for making sense of a problem and bringing a particular kind of tradebased solution into being which might then be worked on in other areas (for an example, see MacKenzie, 2009). That is, other areas might be re-defined at least notionally in line with understandings and expectations made available in relation to the exemplar..But such a treatment of paradigm-exemplars perhaps short-cuts the complexities through which problem-solution relations and their entanglement with markets come to make sense, or form a recognised solution. Barnes, Bloor and Henry (1996: 47) suggest that achieving knowledge takes place through 'ostensive learning' and empirical experience. That is the paradigm-exemplar becomes available for others, for example in the same scientific field, as a settled and agreed upon basis for the production of further work. ${ }^{6}$ Hatherly, MacKenzie and Leung (2008: 136) suggest that Barnes and Bloor are inclined: 'to invoke psychological and sociological processes to explain foreclosure in practices of interpretive flexibility'. Hence at some point and for a time, the paradigm-exemplar comes to be known as what it is through foreclosure. Such foreclosure becomes the basis for the problem-solution relationship to be what it is, but perhaps only provides a limited basis for understanding what might happen over time, in disputes regarding the consequence of a solution or on occasions when a solution appears to become the problem.

\section{Ontological constitution}

A third approach to problem-solution relationships offers an alternative to foreclosure by focusing more closely on the ontologically constitutive nature of problem definitions (Woolgar and Pawluch, 1985). We call this approach ontological constitutive in the following analysis. This line of research challenges any counter assumption that problems pre-date solutions, that solutions are straightforwardly designed to solve problems or that predictable consequences flow from the implementation of solutions. Instead this approach suggests that problems are frequently re-oriented to fit current understandings of the capability and capacity of solutions, problems are pushed to the fore in order to justify solutions and numerous unintended consequences ensue. This suggests a more radically indeterminate approach than Barnes' foreclosure argument, drawing its inspiration from ethnomethodology and ideas of in-principle inconcludability.

The latter argument suggests that any settling of the sense of a matter is a practical and temporary accomplishment within a particular setting in order to get on with the task at hand (Garfinkel, 1967). Extending this ethnomethodological approach, we could consider further Garfinkel's (1967) suggestion of the recursive relationship 
between problems and solutions through which one always falls back into the other (see also, Woolgar and Neyland, 2013). Alternatively, we can find a number of STS works which provide further grounds for exploring ontological re-specification in particular. For example, we could draw on Law and Mol's (1998) work on fluidity, Mol's (2002) work on ontological multiplicity or Cussins (1995) work on complex organisational settings (in her case in healthcare) through which ontology is choreographed. This could provide a basis for re-considering the nature of problemsolution relationships as only provisionally settled.

This distinction between foreclosure and in-principle inconcludability ties in with a long standing debate in STS between approaches which tend to emphasise closure (through stabilization in the Social Construction Of Technology approach, and black boxing in ANT) or radical, on-going uncertainty or indeterminacy (through, for example, ideas of ontological multiplicity or fluidity). It is not our intention to resolve these debates here. However, in considering markets, problems and solutions perhaps both approaches might have something to offer.

On the one hand there may be examples of market problem-solution relationships which appear to lend themselves to analysis as Kuhnian problem-solution paradigmexemplars. For example, as we mentioned, environmental cap and trade schemes initially appeared to inspire a range of further environmental market-based incursions which at least in part sought a transformation of natural entities into trading entities. Cap and trade, for a time, acted as a foreclosed exemplar. On the other hand, there may be interventions characterized by on-going, radical indeterminacy leading to questions of the ontological-constitution of market entities, actors, devices and relationships. For example, in the field of waste management, although the cap remained in place, evidence trading was beset by radical indeterminacy and forms of market failure within its opening trading period (Neyland and Simakova, 2012).

In the following analysis of emerging attempts to introduce a market solution to the problem of online privacy, we will explore two forms of work in which problems, solutions and markets have become entangled. The analysis will explore, first, the work of policy makers attempting to introduce new privacy legislation and foster the grounds for a privacy market, and, second, the work of small start-up firms attempting to contribute to the establishment of a market for online privacy protection. The status of the term market in this analysis derives from research participants who in various ways (specified below) identified themselves as engaged with the online personal data market. In the analysis the multiplicity of problem-solution-market relationships will be considered in relation to the initial three-part analytic scheme we have explored. The analytic utility of issue-problematisation, paradigm-exemplars and ontological constitution will be considered.

\section{An online privacy market?}

In this section we will use our study of online privacy to suggest that this area has been constituted as various kinds of problem in need of market-type solutions. ${ }^{7} \mathrm{We}$ have interviewed 37 representatives from a variety of organisations in the field. This has included privacy start-ups, data protection regulators, network builders, academics in the field and privacy campaigners. The interviews have been semistructured in nature, allowing interviewees to discuss points about their work that they deem relevant, at the same time as enabling us to explore this emerging field. The 
interviews have been conducted in the UK, Ireland, US and mainland Europe. We have also drawn together a substantial corpus of online privacy-related media stories, industry reports and academic research. Our reason for choosing online privacy is that we anticipated this would provide a dynamic and developing field in which market problem-solution relationships are the subject of much current discussion. We imagined prior to the research that engaging with what could be described as the genesis of a market problem-solution would provide an opportunity to consider our research questions with respondents prior to the field becoming settled or easy to represent. This has proven to be both advantageous and problematic as the following analysis will illustrate.

In some ways we have generated our own problem-solution relationship: establishing a field (online privacy) that poses a problem (how to adequately engage with it) and a series of solutions (preceding theories) which to some extent either resolve or redefine the problem. In order to identify relevant discussions of problems and solutions within the interviews and group these together for analysis, we drew on an accumulative coding procedure. This involved reading through the transcripts multiple times and coding interview discussions into topics. Topics were then analysed to draw out discussion of specific problems and solutions, even if different views were expressed regarding these. The problems and solutions drawn out from the transcripts will form the basis for the following analysis.

We will begin our analysis with recent attempts to regulate a market into being for online privacy and then subsequently consider start-ups' attempts to develop products, services and hence a market for online privacy. Herein the precise nature of privacy continues to shift. Although traditional privacy concerns regarding visibility and data collection persist, concerns with invasions of privacy (Neyland, 2006) appear to have been replaced by matters of data flow, control and ownership. We will assess the analytic utility of the preceding theoretical approaches to problem-solution relationships through this data.

\section{Regulating a privacy market into being}

Comparing the regulatory environment for online data management in the US and Europe reveals distinct ways in which the problem and solution of online privacy and its entanglement with markets has been constituted. In the US, discussions continue regarding the regulation of online digital data management organisations such as data brokers. ${ }^{8}$ Despite the industry being estimated to be worth \$US150bn (Steel, 2014), a frequently repeated refrain is that little is known about the way these organisations operate. In 2013 the US Federal Trade Commission (FTC) requested information from data brokers on:

'where the data brokers get their information, what do they do with the information, how do they use it [...] and then who are their customers and what are their customers using the information for... [they are] in a process of analysing the information and drafting a report' (Interviewee 1 , USA, $6^{\text {th }}$ November 2013). ${ }^{9}$

This suggests a particular kind of formulation of problem and solution. A lack of data on data brokers provides a preliminary means to couple problem and solution. The 
types of question being asked, provide a further steer on the imagined nature of the problem of privacy online - that it is focused on data, its collection, its use and purpose. The nature of the entities involved is specified in stark oppositional terms with the data brokers as potential evil doers and online users as potential victims. ${ }^{10}$ This presentation of the problem maps more or less seamlessly onto media stories regarding informational, technical, calculative and/or economic asymmetry which is said to characterise the relationship between data brokers and data subjects. The following typifies this kind of story:

'On one side of the screen is grandma looking for information on arthritis treatments and for gifts for her grandchildren, while on the other side of that screen is a Ph.D. quant from Google, a Silicon Valley start-up or some other company, looking to maximize grandma's value.' ${ }^{11}$

Here the privacy problem becomes understood in market terms; that in order to amass value from data, the data broker firms produce and maintain asymmetries. The FTC suggests a possible future solution for online privacy problems would focus on transparency of data brokers' activities (Brill, 2013), perhaps addressing these asymmetries.

The US Senate (2013) initially appeared to constitute the nature of the problem in a similar manner to the FTC: they suggested the industry that trades in consumer data 'operates behind a veil of secrecy'; that 'many of their practices lie outside the ambit of federal consumer protection laws' (US Senate 2013: iii, 2); and that traditional data-protection approaches were no longer fit for purpose (WEF, 2013: n.p.). Yet, in comparison with the FTC, the Senate (2013) constituted a distinct solution, initiating a bill demanding the industry introduce steps that guarantee the accuracy of consumer data they collect. Accuracy rather than the removal of asymmetries became central for the US Senate. The problem and solution coupling becomes an absence of regulation in a market for data that runs wild. In this way data brokers have been identified as 'the new villain in privacy debates' (Bachman, 2014: n.p.), the central figure in the problem.

This situation might initially appear to encourage the adoption of issueproblematisation as a way of framing problem-solution relationships. This approach could be used to make sense of the situation as a controversy in which antagonist problematisations are opposed to each other (Callon 1981, Callon, Lascoumes and Barthe 2009). As a result it would be possible to trace the actions and spokespersons and entities in the assembled controversy which might enable a particular coupling of problem and solution to come to the fore.

Yet the FTC and Senate are not the only contributors to this policy debate. The President's Council of Advisors on Science and Technology (PCAST, 2014) report constituted a distinct approach to the problem-solution of online privacy, devoting more attention to considering the possibility that curbs on data would play a role in 'inhibiting economic growth,' (PCAST, 2014: xi). Perhaps unsurprisingly, the data broker industry has aligned with the PCAST view, inverting the problem and solution relationship constituted by the FTC and Senate. Data brokers suggest that data sharing is a prerequisite for economic growth, insisting that 'third-party data use and sharing are essential for business success in today's information economy', and the demand 
for regulation is 'unfounded' (Wooley, 2014: n.p.). In this way, the proposed Senate regulation becomes constituted as the problem - one the data brokers would like stopped - leaving the data brokerage industry to carry on as the solution to economic growth. The regulation is positioned as a problem for the market.

So although in a general sense we might draw on issue-problematisation (such as Barthe, 2009) as a means to note that each of the aforementioned activities in some ways contributes to generating recognition that there is a problem requiring a solution, it is not clear that a singular spokesperson, stable assemblage, or a forum for public engagement has yet emerged. Furthermore, online data appears to lack a recognisable public for whom their data is an issue (Marres, 2011). It is also not the case that these regulatory discussions could yet be considered as a means of qualifying (Sjogren and Helgesson, 2007) for example, online data for new kinds of market work through which a solution could be formed; it is the market work which is designated as the problem.

At the same time, the notion of a foreclosed problem-solution paradigm-exemplar (Barnes, 1985) which is acted upon by participants in this field appears notably absent. Indeed what seems most clear is that the problem-solution relationship is characterised by an on-going recursion (Garfinkel, 1967), with ontological constitution paramount in the continual re-casting of the nature of entities involved. However, this recasting is not quite the same as Callon's (2007) continual overflowing and reframing. Instead, the re-casting of what the nature of things is, generates an opposition between the initial positioning of evil (data brokers) and innocence (victims of data brokers) and subsequent positioning of evil (over regulation) and heroism (through data brokers as heroic figures of capitalism, proving to be the engines of economic growth). In this sense it is a recursive recasting falling in on itself - rather than an overflow.

This US regulatory picture contrasts with developments in Europe where the regulatory constitution of the problem and solution has been distinct. Discussions regarding the adoption of the revised European Data Protection Regulation (EC 2012) continue. ${ }^{12}$ In this revision, the appropriate focus for Data Protection appears to have shifted from a historical privacy concern with the regulation of state surveillance to also incorporate the regulation of online commercial data practices and processes. The revisions are also characterised at least in part by constituting the problem-solution of Data Protection in terms of the difficulty of regulating. First, there has been a recognised problem with figuring out the nature of the privacy problem-solution and what ought to form the content of regulation:

'There is a long way to go in terms of getting this legislation right. [...] The regulation that is currently being considered by the European legislator, is a very, very long shopping list. Every time that one makes a point about what should be in it, it just gets longer and nothing gets removed from it - because it is a regulation it will apply to everybody in a uniform way' (Interviewee 2; a UK regulator, $8^{\text {th }}$ April 2014).

Second, a problem with the regulatory responses available to Data Protection offices, the appropriate cost-value involved in these responses and what these might mean to data brokers has been argued back and forth between regulators and data brokers: 
'The trouble with Google is, they are so rich that you will fine them as much as you can possibly fine them, and it is just water off a duck's back' (Interviewee 2; a UK regulator, $8^{\text {th }}$ April 2014).

Third, these discussions are also in part characterised by an on-going recognition that the task of Data Protection regulators in the EU and elsewhere is becoming more challenging. According to our interviewees resources for Data Protection regulators are stretched and budgets squeezed. At the same time, commercial entities handle ever more data, at ever greater scale and speed, incorporating an ever changing array of, for example, algorithms for sifting, sorting, mining and scraping data. As a result Data Protection regulators have come to recognise the difficulties of providing adequate regulation and protection. ${ }^{13}$

The nature of the problem-solution here has been directly incorporated into a market logic - that it might be through the online data market that the problem of overstretched and under-funded regulators might be resolved. Hence along with direct regulation through Data Protection legislation, efforts have also been made to foster an environment in which individual users might be encouraged to recognise on a larger scale their rights towards their online data. In theory, through establishing different and closer relationships with data management organisations, users might further contribute to the oversight of data management organisations. And this might create a redefinition of the problem of online privacy. The problem might now be characterised as an absence of value held by the original source of online data. The solution that follows would be to create a situation in which the original source of data, for example people doing online searches, could hold a proxy property right in that data, at least in recognising that it has a value to someone or some organisation.

The prospects for a new data market-solution to emerge can be analysed in issueproblematisation terms. Drawing on Callon and Muniesa's (2005) work, for a market assemblage to operate, things need to be calculated, but must also be made calculable. That is, for an entity to be calculable, requires that it is detached from its conventional associations and then ordered within a single space into new associations, such that new results - value - might be extracted. For online data to become the subject of a more privacy-sensitive set of market exchanges, would require substantial reorientation of the means through which data currently flows. Data's free flow into brokers, without users' awareness or control and without any retained attachment to the data would need to change. So would the ordering of data into a single space through, for example, data mining and the use of data analytics to profile users. The use of this data to then sell users (apparently) relevant goods through the purchase of online advertising space on behalf of clients, would also require transformation. For a market solution to emerge using these terms, would require cutting data brokers' attachment to data, re-forming attachments between users and their data and working out a means to enable users to then extract results - such as value - from their own data. Alternatively, users could be placed in a position to deny data brokers the opportunity to generate value from their data.

For this kind of issue-problematisation as a market assemblage to endure would require a pervasive redefinition of the entities involved in online activity. In this way, issue-problematisation and ontological constitution would need to be drawn together 
to make sense of the action. The very nature of people online, their actions, the data produced, who owns or controls or profits from that data, who or what holds the data and in what form, for what use, would all need to change for a privacy-sensitive market for online data to emerge. Notably privacy would also require re-definition through new forms of data ownership and control. Furthermore, national and EU Data

Protection regulators are not classical market actors - their ability and remit to shape a market is at best unclear. Thus far their approach to market shaping has involved support and encouragement for the formation of organisations - mostly start-ups that might introduce a set of market arrangements in which online privacy might become a recognised good. This has included: aiding the development of statesupported start-ups such as Mydex ${ }^{14}$ (a community interest company); the development of the midata Innovation $\mathrm{Lab}^{15}$; and collaboration with businesses such as Allfiled. ${ }^{16}$ Further support has arrived through Data Protection regulators turning up to participate and speak at meetings organised by the emerging community of online privacy start-ups. ${ }^{17}$

In a general sense we can note that these activities act as a form of issueproblematisation. Activities are taking place through which a problem is specified and qualified at least for discussion: it is to be a problem of European politics and legislation. Yet, in a similar manner to the US regulatory field, it still appears difficult to identify a spokesperson, or an obligatory point through which the formulation of the problem should pass (Callon, 1989). There also appears to be no specific forum of direct participatory or dialogic democracy (Callon, Lascoumes and Barthe, 2009) for users. So far, appeals to new forms of participation with users holding organisations to account, remain at the proposal stage. ${ }^{18}$

Efforts to foster an environment for creating online, privacy-interested start-ups could perhaps move the regulatory debate towards forms of market qualification (Sjogren and Helgesson, 2007), but at present there remains no specific device such as a taxbreak for privacy-focused start-ups through which they might be qualified for participation in market work. Instead, at the moment it seems that regulators might favour something akin to Barnes' (1985) treatment of a Khunian paradigm-exemplar. The focus seems to be directed towards a kind of idealised start-up, offering a problem-solution pairing which could be engaged and built upon. For regulators this kind of paradigm exemplar, it seems, would go beyond a single innovation and step aside from arguments regarding economic growth to provide a solution that could shape the online data market by providing an approved set of actors, processes and relationships, from which other online actors, such as large data brokers, might come to re-define their actions and the expectations of users.

However, any form of foreclosure around such a paradigm-exemplar is still some way off. At present the problem-solution and market entanglement appears characterised by continual ontological constitution, characterised by on-going changes in the basis for making sense of the entities involved (from data to users to value). The result is a continual ontological re-specification of participants (Woolgar and Neyland, 2013). At the same time as this re-specification work is taking place, many other actors and actions are also taking place. Data brokers continue to grow, data analytics continues to change, and the auctioning of online advertising space predicated on extracting value from users' data, continues to expand. The singularity of an agreed-upon 
paradigm-exemplar that works, remains elusive as we will now see in turning attention to the emerging field of data start-ups.

\section{Data start-ups and the market for privacy}

A number of start-up organisations have emerged in Europe and the US in the last few years which each propose particular relations of problem-solution and market for engaging online privacy. These start-ups are not entirely separable from the regulatory discussions we just explored. For instance, in Europe, some of these startups can trace their origins directly to attempts to create an attractive environment in which they might emerge (as we mentioned above: Mydex, the midata project). Other start-ups are keeping a close eye on continuing discussions regarding the adoption of the revised EU Data Protection Regulation (EC 2012). And in the US, a new range of products, services and start-up organisations, have proposed answers (of a sort) to the problem constituted by the FTC and Senate of how to regulate privacy without inhibiting economic growth.

The products and services currently being developed which each propose a particular kind of solution and hence a particular definition of the problem of online privacy, can be crudely grouped into three: data vaults, tracking protection, and online reputation management. ${ }^{19}$ These products and services each formulate the nature of the problem-solution as a need to put the individual in control of their personal data online. The emerging market for these products and services is imagined as one in which new relations of data, control and value are brought into being. As yet, a single paradigm-exemplar which might stand in as a viable problem-solution coupling from which others work, has yet to emerge. Instead, ontological constitution seems paramount with a continuing re-specification between different start-up firms of the nature of data, control, value, online users and what might constitute privacy. For example, tracking protection and reputation management companies can offer to put online users back in control of their identity, or their reputation, or repair problems once they have been notified, try and ensure that data is not collected, or that it is deleted after it has been made problematically public.

In order to analyse the problem-solution of privacy and market entanglement in more detail, we will turn attention to one particular type of product: data vaults. ${ }^{20}$ As the product's name implies, the vault is promoted as providing a secure store of personal information. Different data vault companies bring into being very different notions of online privacy problem-solutions through the way they propose to manage users' consolidated data. For example, the UK based company Start-up $3^{21}$ provides individual customers with data vaults to assemble and manage their data. At the same time, the company has developed a product that assists their business customer (a well-known consumer website) in helping individuals to find the best deal for a product they want (such as bank interest rates or energy tariffs). The website handles over 13 million users a month and it compares the deals their users currently have with deals available. The Senior Project Manager at Start-up 3 explains:

'[Our vault] knows the deal you're on, and it asks the question, 'If I can find you a better deal, how much would it take to make you switch?' [...] And it allows you to pick a number, and insert that into personal data store at your convenience, so you decide it's your energy, your money, you decide how and 
where you're going to spend it' (Interview with Start-up 3, UK, $11^{\text {th }}$ October 2013).

Start-up 3 then knows more about users than a conventional data brokerage firm which relies on tracking users and the websites they visit in order to classify users. Start-up 3 doesn't need to draw together such inferences as its users sign-up by name, with an address and other identifying characteristics and then manage, for example, their insurances, savings, loans, energy tariffs and so on through the personal data vault. Start-up 3 then looks to maximise the value of this data, not by selling it, but instead by aggregating users' preferences and effectively negotiating and brokering deals on users' behalf with other firms. So if 10,000 users decide they want a twoweek holiday in Spain in August, Start-up 3 will take that data as an opening bargaining chip to negotiations with holiday firms and then report back to users the best deals they could strike. This interaction between a user's data vault and the business that operates the vault constitutes a distinct take on what we have summarily termed online privacy. The vault is presented as a market solution which understands the problem of online privacy in terms of power and control. The solution envisaged is the rise of a 'personal information industry' (Chahal 2014: n.p.), which will 'empower' consumers with their personal data and 'catalyse a revolution in marketing. 22

Reattaching property rights to users' data in the manner that a data vault proposes, encloses (as the metaphor of a vault suggests) the data. From a free flow to be picked up, analysed and sold on by data brokers, data instead becomes a more stationary entity. This enclosure allows a tighter specification of the entities involved. The coupling of problem-solution must operate in a similar manner to Caliskan and Callon's (2010) analysis of experimental economics in which the conditions of the experiment must be extended from the laboratory into the world beyond in order to accomplish the same effect. Here, the conditions of data control must be enclosed within the vault and centred on users' preferences and then only extended into the world when those same conditions can be met beyond the vault (for example in anonymised aggregated data). Extracting value depends upon the maintenance of these conditions. If control can be maintained in ensuring user preferences are acknowledged in accumulating data and seeking offers, for example, from travel companies, then value might accrue to the start-up firm and to some extent to the user, who might attain a form of privacy through control and get a cheaper holiday. ${ }^{23}$

Except that, in a reverse of Marres' (2011) work on smart metres - where the basis for user entanglement must be ease of participation - here the online user must sign up to become entangled in this particular problem-solution relationship and continually cast and re-cast their preference for data management. Once entangled, then users' online experiences become mediated by a device (a data vault) which specifies a preferred order to be accomplished (a user placed in control of their data). This particular specification of the issue-problematisation of privacy will only become recognised at the moment when (or if) a sufficient number of users sign up for this kind of entanglement. Although Marres (2005) adopts the slogan 'no issue no public', here we could suggest a reformulation of 'no issue no market.'

In this way, the data vault cannot be analysed solely in terms of issueproblematisation, in the sense of offering a dialogic space for the communication, 
uptake, contestation or discussion of problems (Callon, Lascoumes and Barthe, 2009). And from among the data start-ups there is yet to emerge a paradigm-exemplar (Barnes, 1982; 1985). In this way, there is not an approved set of actors, processes and relationships from which other areas might be re-defined in line with understandings and expectations made available in relation to the paradigm-exemplar. It is also not quite the case that the field of data start-ups is characterised by such a recursive problem-solution relationship (Garfinkel, 1967) as data regulation. In discussions around data regulation it appeared that the regulators considered the data broker industry to be the problem, then the industry would note that the regulators' proposed solution was the problem, which would then lead the regulators to suggest that this demonstrated the data industry's problem in seeking to profit from maintaining current asymmetries, and so on.

In place of such rapid and consistent recursion, the data start-ups offer a particular ontological constitution of problem and solution that involves a re-specification of the nature of almost all the entities involved. Hence the user is now to be understood as privacy-interested (signing up to have a data vault) but also price conscious (for example, wanting a good deal on their energy tariff or a good price for their summer holiday). And privacy becomes re-specified, with specific enclosures formed by vaults and movement of data out into the world only enabled once the effect of enclosure can be guaranteed beyond the vault. In this way privacy can now be presented as online data control, an opportunity to be sent fewer advertisements and as an opportunity to switch energy providers or buy a summer holiday and save money. The re-specification is broad: privacy is not only turned into a market opportunity, it is now constituted as the future of marketing.

\section{Discussion and Conclusion}

Within the field of online privacy, problems, solutions and market entanglements are brought into being in multiple forms. In the preceding analysis we have explored this multiplicity by drawing on three theoretical positions that we have referred to as paradigm-exemplar, issue-problematisation and ontological constitution. These have each demonstrated some analytic utility for grasping the complexity of the field with which we have engaged.

US regulators and the data broker industry response to the prospects of regulation, each ontologically constitute a certain nature for the problem from which we can see that an assured and certain solution is now available. There is the assured certainty of the Senate which makes it clear that regulation is required to achieve online privacy and the equally assured but contradictory certainty of PCAST and the data driven marketers who identify regulation as a problem from which they must be freed to pursue their solution to the problem of absent economic growth. Issueproblematisation draws our attention to the possibility that these various and contradictory certainties might require reconciliation. However, there has yet to emerge a single forum in which these standpoints might be discussed, and few opportunities for online users to participate in a dialogue. The overall effect of having multiple, assured, but contradictory certainties appears to be an on-going recursion whereby problem and solution continually fall into each other. 
Turning attention to EU data regulation highlights a distinct form of ontological constitution. The assured and contradictory certainty of problem-solution couplings in the US sits alongside non-assured uncertainty among EU Data Protection regulators. The latter hope to see privacy protected, but remain cautious about the best means to achieve such, effectively spreading their risks by 'investing' in a portfolio of potential solutions, including EU regulation, helping privacy-focused start-ups and making supportive appearances at emerging community events. Furthermore, start-ups in the field are appearing rapidly, but with a range of distinct ways of constituting problemsolution and market relationships in online privacy. Start-ups developing data vaults constitute users as data controllers or owners, interested in their own privacy and the opportunity to financially gain from a form of privacy. For data vaults to introduce the kind of revolution in marketing sought by these start-up organisations, would require a pervasive re-specification of entities as diverse as online users, data, privacy and marketing.

Taking online data as our example of the entanglement of problems, solutions and markets opens up three questions which we think have some value for explorations of other similar entanglements. First, analysing problem-solution relationships and markets using theories of issue-problematisation poses challenging questions. For example, although a central feature of studies of issue-problematisation is how various groups come together and how an issue becomes recognised as a valid or reasonable question to account for, it remains to be explored to what extent the marketization of problems could be addressed using similar terms. Although it might be said that the introduction of a market-based solution to a public problem incorporates a concern for the public affected by the problem and seeks an effective and efficient use of public funds in achieving a solution, 'the public' is most often treated as a set of delegated beneficiaries on behalf of whom a solution will be sought.

The public are aggregated in such a way as to be pre-pacified prior to any market action. In this way, the public are not often invited to participate in the discussion, negotiation or establishment of market-based solutions and the resolutions produced are more or less imposed upon the population. Market reforms of the welfare state, for example, do not generally emerge from public calls for reform, the public are not invited to participate in a dialogue about reforms and indeed it is frequently the case that particular couplings of problem and solution become noted as the problem that requires resolution (see, for example, critiques of neoliberal government, summarised by Venugopal, 2015). Questions remain as to who would occupy a position as a recognised spokesperson for the public in creating a market issue-problematisation or to what extent market-type solutions are characterised by a concern for the kind of democratic questions of inclusion and voice noted by STS authors (particularly in Callon, Lascoumes and Barthe's (2009) work on hybrid forums)?

Second, engaging with problems, solutions and markets through theories of paradigmexemplars raises questions of the conditions that would need to emerge for an exemplar to succeed. For a Kuhnian paradigm-exemplar to emerge among privacyinterested online data start-ups would require significant commandment and coordination of resources in terms of finance, data and number of users, before data brokers would begin to pay attention or others in the field would begin to rework their activities in relation to the paradigm-exemplar. At the same time, co-ordination in market based problem-solution relations remains somewhat hard to characterise. 
Indeed it could be argued that a central justification for market-type solutions is to shift away from the very notion of co-ordination (at least by the state). Instead, market solutions often involve shifting out costly and time consuming co-ordination activities to the market in order to enhance efficiency, or at least reduce state costs or make more from the limited budgets of, for example, data protection regulators and enhance effectiveness, at least in line with the idea that several competitors will emerge and offer different types of solution, and customers, users or the public will be the ones who decide which solution is best. The pertinent co-ordination question for STS approaches to problem-solution relationships when markets are involved then appears to be: how can this simultaneous presence and absence of co-ordination be articulated?

Third, taking on theories of ontological constitution in entanglements of problems, solutions and markets, can risk under emphasising questions of normativity. In looking at the example of online privacy, particular kinds of normative questions have emerged around, for example, who ought to own data, what ought to happen to data, and how should data brokers be regulated (if at all). At the same time as these normative issues are raised, prioritisations are also continually made between, for example, what would be most economically efficient (including how regulators should spend their limited budget), or effective (including how growth in the data market can be encouraged, through enabling data brokers to have free access to data or in fostering the emergence of new privacy-inclined online data start-ups).

In other market type interventions questions are posed of, for example, poverty, health, and crime, which would appear to raise similar normative challenges when combined with economic prioritisations. Our consideration of STS approaches to problem-solution relationships has not thus far enabled us to engage with these normative prioritisations to any great extent. In considering the ontological respecification of entities entangled in problem-solution relationships with markets we have not yet found a coherent means to pose questions of ontology and normativity (and indeed onto-normativity appears a relatively recent concern for STS in general; Mol 2012). Hence our final question for engagements between STS treatments of problem-solution relationships and markets is: how to make sense of problemsolution relationships and the normative questions that arise in engaging with the economic prioritisations characteristic of market interventions?

\section{Acknowledgements}

Many thanks to two anonymous reviewers and the journal editors for their helpful comments on a previous version of this text. The research project MISTS, led by Daniel Neyland, that led to these results has received funding from the European Union Seventh Framework Programme [FP7/2007-2013] under grant agreement no. 313173.

\section{References}

Angwin, J. and Steel, E. (2011) 'Web's Hot New Commodity: Privacy', Wall Street

Journal, February 27.

http://www.wsj.com/articles/SB10001424052748703529004576160764037920274 accessed June 26, 2013. 
Bachman, K. (2014) 'Confessions of a Data Broker.' AdWeek. March 25. http://www.adweek.com/news/technology/confessions-data-broker-156437, accessed April 14, 2014.

Barnes, B. (1982) T.S.Kuhn and Social Science. New York: Columbia University Press.

Barnes, B. (1984) Challenging the Rationalist Myth. Available from: http://staff.bath.ac.uk/mssdep/Barnes\%20on\%20Kuhn.htm. Originally published in Listener, $19^{\text {th }}$ April, 1984.

Barnes B. (1985) 'Challenging the Rationalist Myth', pp.83-100 in Skinner, Q. (ed.) The Return of the Grand Theory in the Human Sciences, Cambridge University Press.

Barnes B., Bloor, D. and J. Henry (1996) Scientific Knowledge: A Sociological Analysis, London: Athlone.

Barthe, Y. (2009) Framing nuclear waste as a political issue in France. Journal of Risk Research 12(7-8): 941-54.

Brill, J. (2013) 'Demanding Transparency from Data Brokers.' The Washington Post, August 15

Brustein J. (2012) 'Start-Ups Aim to Help Users Put a Price on Their Personal Data', The New York Times, 12 February. http://www.nytimes.com/2012/02/13/technology/start-ups-aim-to-help-users-put-aprice-on-their-personal-data.html, accessed September 2, 2013.

Çalışkan, K. and Callon, M. (2010) Economization, part 2: a research programme for the study of markets, Economy and Society 39(1):1-32.

Callon, M. (1986) Some elements of a sociology of translation. In Law, J. (ed) Power, action and belief: a new sociology of knowledge? London: Routledge, pp.196-223.

Callon, M. (1989), Society in the Making: The Study of Technology as a Tool for Sociological Analysis. In: Bijker, W., Hughes, T. and Pinch, T. (eds.), The social construction of technological systems, Cambridge, Mass.: MIT Press.

Callon, M. (1998) The Laws of the Market. Oxford: Blackwells

Callon, M. (2007) An Essay on the Growing Contribution of Economic Markets to the Proliferation of the Social. Theory, Culture, Society. 24: 139-63.

Callon M. (2009) Civilizing markets: Carbon trading between in vitro and in vivo experiments, Accounting, Organizations and Society 34 (3-4): 535-548.

Callon, M., P. Lascoumes, and Y. Barthe. (2009) Acting in an Uncertain World: An Essay on Technical Democracy. Boston, USA: MIT.

Callon, M. and Muniesa, F. (2005) Economic Markets as Calculative Collective Devices, Organization Studies 26(8): 1229-50

Callon, M., Méadel, C. and Rabeharisoa, V. (2002) The economy of qualities. Economy and Society 31:194-217.

Chahal, M. (2014) 'Taking Back Control: The Personal Data Economy', Marketing Week, 12 March. http://www.marketingweek.co.uk/analysis/essential-reads/takingback-control-the-personal-data-economy/4009679, accessed March 19, 2014.

CBS News. (2014) 'The Data Brokers: Selling Your personal Information' http://www.cbsnews.com/news/the-data-brokers-selling-your-personal-information/ accessed April 22, 2014

Cochoy, F. (2009) Driving a Shopping Cart from STS to Business, and the Other Way Round: On the Introduction of Shopping Carts in American Grocery Stores (1936-1959). Organization 16 (1):31-55.

Cohen, M., J. March, and J. Olsen (1972) A Garbage Can Model of Organizational Choice. Administrative Science Quarterly 17:1-25. 
Cussins, C. (1995) Ontological Choreography: Agency Through Objectification in Infertility Clinics, Social Studies of Science, (26) pp. 575-610.

Dewey, J. (1938) Logic: The Theory of Inquiry, NY, NY, USA: Henry Holt and Company.

(EC) European Commission (2012). 'Commission Proposes a Comprehensive Reform of the Data Protectio Rules' http://ec.europa.eu/justice/newsroom/dataprotection/news/120125 en.htm, accessed October 10, 2013.

FTC (2012) 'FTC to Study Data Broker Industry's Collection and Use of Consumer Data.' December 18. http://www.ftc.gov/opa/2012/12/databrokers.shtm, accessed September 19, 2013.

Garfinkel, H. (1967) Studies in Ethnomethodology. Prentice Hall, NY, USA.

Hatherly D, MacKenzie D., and D. Leung (2008) 'The Finitist Accountant', pp.131160 in Living in A Material World (eds. T. Pinch and R. Swedberg). Cambridge, Mass.: MIT Press.

Kjellberg, H. and Helgesson, CF (2007) The mode of exchange and shaping of markets: Distributor influence in the Swedish post-war food industry. Industrial Marketing Management 36 (7):861-878.

Kuhn, T. (1962) The Structure of Scientific Revolutions. Chicago, USA: University of Chicago Press.

Latour, B. (1993) Ethnography of a High-Tech case: About Aramis. In P. Lemonnier (ed) Technological Choices - Transformations in Material Culture since the Neolithic, London: Routledge \& Kegan Paul.

Law, J. and A. Mol. (1998) On Metrics and Fluids - Notes on Otherness, in R. Chia (ed.) Organised Worlds - Explorations in Technology and organisations with Robert Cooper. London: Routledge

Lee, J. (1984) Innocent victims and evil-doers. Womens Studies International Forum 7, 69-83

MacKenzie, D. (2009) Making Things the Same: Gases, emission rights and the politics of carbon markets. Accounting, Organisations and Society. 34: 440-55

March, J. (1981) Decisions in Organizations and Theories of Choice. In A. H. Van de Ven and W. F. Joyce (eds) Perspectives in Organization Design and Behavior, New York: John Wiley \& Sons.

Marres, N. (2011) The costs of public involvement Everyday devices of carbon accounting and the materialization of participation. Economy and Society, 40(4): 510533

Marres, N. (2012) Material Participation. London: Palgrave-MacMillan.

Marres, N. (2005) No Issue, No Public. PhD Thesis.

Marres, N. and Lezaun, J. (2011) Materials and Devices of the Public. Economy and Society, 40(4): 489-509.

Mol, A. (2002) The Body Multiple: ontology in medical practice. London: Duke University Press

Mol A (2012) Mind your plate! The ontonorms of Dutch dieting. Social Studies of Science. 43(3): 379-96.

Morozov, E. (2013) To Save Everything, Click Here: Technology, Solutionism and the Urge to Fix Problems That Don't Exist. PublicAffairs.

Muniesa, F. and Callon, M. (2007) Economic Experiments and the Construction of Markets, in MacKenzie, D., Muniesa, F. and Siu, L. (eds) Do Economists Make Markets? Oxford: Princeton University Press.

Neyland, D. (2006) Privacy, Surveillance and Public Trust, London: PalgraveMacmillan. 
Neyland, D. and E. Simakova (2012) 'Managing Electronic Waste: A Study of Market Failure' New Technology, Work and Employment, 27(1): 36-51

Neyland, D. and E. Simakova (2015) 'The Mosquito Multiple' in I. Dussauge, CF Helgesson and F. Lee (eds) Value Practices (Oxford University Press: Oxford) pp. 136-50.

PCAST (2014) Big Data and Privacy: A Technological Perspective. Executive Office of the President President's Council of Advisors on Science and Technology. http://www.whitehouse.gov/sites/default/files/microsites/ostp/PCAST/pcast_big_data and_privacy__ may_2014.pdf, accessed May 12, 2014.

PC Advisor (2013) 'Personal Data Vaults Put You in Control of Your Data Online.' http://www.pcadvisor.co.uk/news/internet/3369859/personal-data-vaults-put-you-incontrol-of-your-data-online/, accessed September 2, 2013.

Robin F. (2013) 'The Emerging Market That Could Kill the iPhone - Fortune Tech.' CNNMoney. http://tech.fortune.cnn.com/2012/08/01/iphone/, accessed July 9, 2013.

Singer (2013) 'A Data Broker Offers a Peek Behind the Curtain.' The New York Times, August 31.

Sjögren, E. and Helgesson, C-F. (2007) The Q(u)ALYfying hand: health economics and medicine in the shaping of Swedish markets for subsidized pharmaceuticals. Sociological Review 55(2): 215-240

Steel, E. (2014) 'Data Brokers Change Labels Describing Poor', The Financial Times, March 23

US Senate. (2013) 'A Review of the Data Broker Industry: Collection, Use, and Sale of Consumer Data for Marketing Purposes; http://consumercal.org/wpcontent/uploads/2013/12/senate_2013_data_broker_report.pdf accessed February 4, 2014

Vaidhyanathan, S. (2006) Rewiring the 'Nation': The Place of Technology in American Studies, American Quarterly, Vol.58, Number 3, pp. 555-567

Venugopal, R. (2015) Neoliberalism as Concept Economy and Society 44(2): 165-87.

WEF. The World Economic Forum. (2013) 'Unlocking the Value of Personal Data:

From Collection to Usage'. Report. http://www.weforum.org/reports/unlockingvalue\%20\%20personal-data-collection-usage. accessed September 2, 2013.

Wooley, L. (2014) 'DMA Responds to Op-Ed Attacking Commercial Data Use.' Direct Marketing Association. http://blog.thedma.org/2013/08/19/dma-responds-toop-ed-attacking-commercial-data-use/, accessed April 17, 2014

Woolgar, S. and Neyland, D. (2013) Mundane Governance. Oxford: Oxford University Press.

Woolgar, S. and Pawluch, D. (1985) Ontological Gerrymandering: The Anatomy of Social Problems Explanations, Social Problems (32:3), pp. 214-27.

\footnotetext{
${ }^{1}$ See for example: https://www.gov.uk/guidance/social-impact-bonds

${ }^{2}$ See for example Neyland and Simakova (2015)

${ }^{3}$ Alternatives to these three positions include Vaidhyanathan's (2006) work on techno-

fundamentalism and Morozov's work on solutionism and Cohen et al (1972) and March's (1981) work. These texts are not further explored here due to space constraints and because they were not central to our developing argument.

${ }^{4}$ For an alternative example of Actor-Network Theory and problems and solutions, see Latour (1993).

${ }^{5}$ This work draws on Dewey's (1938) assertion that the formation of a problem involves a process of making an indeterminate situation into a determinate one.

${ }^{6}$ In a similar manner to stabilization in the Social Construction of Technology (SCOT) approach.

This will not be explored in greater detail in this paper due to space constraints.
} 
${ }^{7}$ We do not engage with extensive analysis of the literature on privacy in this paper. Instead privacy is treated as an empirical focal point. For an STS approach to privacy, see Neyland (2006).

${ }^{8}$ Although data brokers prefer another name - 'marketing firms' (CBS News 2014), or 'marketing technology companies' (Singer 2013).

${ }^{9}$ Also see FTC (2012)

${ }^{10}$ For more on the constitution of innocent victims and evil-doers, see Lee (1984).

${ }^{11}$ From: http://bits.blogs.nytimes.com/2014/05/05/white-house-tech-advisers-online-privacyis-a-market-failure/? $\mathrm{r}=0$ accessed $17^{\text {th }}$ July, 2015

${ }^{12}$ See for example: http://europa.eu/rapid/press-release STATEMENT-15-5257 en.htm

${ }^{13}$ See, for example: http://www.telegraph.co.uk/technology/internetsecurity/10692265/Europe-backs-stronger-data-protection-rules.html

${ }^{14}$ https://mydex.org/

${ }^{15} \mathrm{https://www.gov.uk/government/news/businesses-get-creative-with-consumer-data-at-the-}$ midata-innovation-lab-launch; http://www.midatalab.org.uk/

16 https://www.allfiled.com/news/

${ }^{17} \mathrm{http}: / /$ personalinformationeconomy.ctrl-shift.co.uk/

${ }_{18}$ Although the European political system has discussed and developed legislation, this is not the kind of innovative or direct participatory fora imagined in the use of the term hybrid forums.

19 The classification is rather crude but it serves the purpose of introducing the scope of the products. For media coverage of the products see Angwin and Steel (2011), Brustein (2012), Robin (2013), PC Advisor (2013).

${ }^{20}$ There are a number of other products and services that could have been included here. We chose data vaults for the purposes of fitting the analysis into a single paper and because this service is prominent in this emerging field.

${ }^{21}$ Similar products are developed by Mydex (https://mydex.org/), Payoga (http://www.paoga.com), Qiy (https://www.qiy.nl/), Azigo (https://azigo.com/my/).

22 The name of a session at the Personal Information Economy event held on London in March 2014

${ }^{23}$ A parallel can be drawn here with market studies work in which consumers' identities are configured through the transaction of goods (see Callon et al, 2002, Cochoy, 2009, Kjellberg and Helgesson, 2007) 